\title{
Cancer in pregnancy
}

\author{
Arun Chaturvedi
}

Received: 21 November 2009 / Accepted: 23 November 2009

(C) Association of Surgeons of India 2009

The occurrence of cancer in pregnant women raises challenging issues and dilemmas for the treating clinician. Diagnostic delays, compromised diagnostic options and difficult medical, ethical and psychosocial issues are part of this challenge [1].

Where the continuation of pregnancy is not desired by the mother and the family, decisions regarding cancer management may be simpler. However, when a safe outcome of pregnancy is desired for both the mother and the baby, the management of the associated cancer needs to be modified. The use and timing of various therapeutic modalities has to be considered carefully. Obstetric management for women with cancer and long-term side-effects of anticancer treatment on the newborn are other important considerations.

The article appearing in the current issue has deliberated on several of these important details. However, several site-specific concerns would need to be addressed by the treating clinician. As mentioned by the authors, it is difficult to bring all of it together in a single article. A brief mention of the management of breast and gynaecological cancers, with appropriate references [2-5], would have been useful for the readers of this paper.

The presence of certain unique pathological conditions associated with pregnancy and important in the differential diagnosis of pelvic masses also needs to be mentioned. These ovarian masses which are specific to pregnancy

\section{A. Chaturvedi}

Department of Surgical Oncology,

Sahara India Medical Institute Ltd., Lucknow, India

A. Chaturvedi $(\square)$

E-mail: drchatur@yahoo.com
(Luteoma of pregnancy and Theca Lutein cysts) regress postpartum [3]. Hormonal influence of pregnancy also causes difficulty in differentiating serous low malignant potential tumours of ovary from frankly invasive carcinoma. Emergency surgical interventions and obstetric complications are especially associated with dysgerminoma in pregnancy.

The need for multidisciplinary involvement and decision making in pregnant women with cancer cannot be overstressed. The recently published clinical recommendations of the European Society of Medical Oncology (ESMO) highlight several of these very important issues relating to the diagnosis, treatment and follow-up of cancer in pregnancy [6].

\section{References}

1. Schover LR (2000) Psychosocial issues associated with cancer in pregnancy. Semin Oncol 27:699-703

2. Zanotti KM, Belinson JL, Kennedy AW (2000) Treatment of gynecologic cancers in pregnancy. Semin Oncol 27:686-698

3. Tewari KS (2007) Cancer in pregnancy. In: Clinical Gynecological Oncology. Disaia PJ, Creasman WT (Eds.), 7th edition, Elsevier 476-531

4. National Comprehensive Cancer Network (NCCN) Clinical Practice Guidelines in Oncology (2009). Breast Cancer 1:MS37-MS39

5. Mir O, Berveiller P, Ropert S, et al. (2008) Emerging therapeutic options for breast cancer chemotherapy during pregnancy. Ann Oncol 19:607-613

6. Pentheroudakis G, Pavlidis N, Castiglone M (2009) Cancer, fertility and pregnancy: ESMO clinical recommendations for diagnosis, treatment and follow-up. Ann Oncol 20 (suppl 4):iv178-iv181 